\title{
La presencia de lo ausente. Claves fónicas para la traducción shakesperiana
}

\author{
John D. Sanderson ${ }^{1}$
}

Universidad de Alicante

\section{Resumen}

La habitual dicotomía sobre traducción para la publicación o para el escenario cuando se trata de un texto teatral es cuestionada en este artículo. Se aporta una fundamentación teórica en la que confluyen traductólogos, lingüistas y profesionales de la traducción teatral que deliberan sobre la importancia de la adecuación oral de los textos meta resultantes. Se realiza un análisis lingüístico de diversos fragmentos de obras del dramaturgo más representado de todos los tiempos, William Shakespeare, en las que se percibe un propósito de producir un efecto fónico mediante el uso de figuras iterativas, y se comparan diversas traducciones al español para evaluar las estrategias aplicadas. La hipótesis de trabajo es la demostración de que una traducción teatral ha de considerar la traslación de los aspectos formales con repercusión en la enunciación oral a un mismo nivel de importancia que la carga semántica individual del léxico utilizado. Su identificación en el texto origen gracias a la nomenclatura canónica de figuras retóricas permitirá deducir la intencionalidad original y plantear recursos traductores para que se produzca un efecto equivalente en los textos meta.

\section{Palabras clave}

Traducción teatral- Shakespeare - figuras retóricas.

\begin{abstract}
${ }^{1}$ John D. Sanderson es Doctor en Filología Inglesa por la Universidad de Alicante, donde imparte Traducción Audiovisual, además de ser el director académico del Máster en Arte Dramático Aplicado UA. Ha publicado dos libros y diversos artículos sobre traducción teatral. Seis traducciones suyas al español de obras de William Shakespeare y una de Thomas Middleton se han puesto en escena.
\end{abstract}


The usual dichotomy about 'page or stage' when referring to theatre translation is questioned in this article. A theoretical basis is supplied with translation theoreticians, linguists and theatre professionals joining in to reflect on how important the oral suitability of target texts is. A linguistic analysis is carried out of several fragments of plays by William Shakespeare, the most performed playwright of all times, where a purpose of producing a phonic effect by means of iterative rhetorical figures is perceived; several translations into Spanish are compared in order to evaluate the applied strategies. The working hypothesis is the proof that a theatre translation should consider transferring formal features which have an effect on oral performability as important as the individual semantic load of the words used. Being able to identify the figures in the source text thanks to the canonical rhetorical nomenclature will allow the translator to infer the original intentionality and apply strategies so that an equivalent effect may take place in the target texts.

\section{Keywords}

Theatre Translation- Shakespeare- Rhetorical Figures.

La obra teatral es una tipología textual cuyo objetivo último, la representación, genera una particular sensibilidad hacia su enunciación oral que suele estar presente en todo su proceso creativo. En un texto dramático se pueden encontrar espaciadamente composiciones micro o macrotextuales cuya finalidad es producir un efecto fónico determinado cuyo valor semántico es equiparable al significado atribuido individualmente a las lexías que las conforman. David Johnston, traductor de la obra de Ramón del Valle-Inclán al inglés, opina con respecto a la peculiaridad del texto teatral: «It is the performative and talismanic rather than the referential and locutionary aspects which are highlighted as being of impact. Language has become sound» (Johnston, 2000:98). Las prioridades quedarían establecidas, y más aún si nos referimos al dramaturgo más universalmente representado, William Shakespeare, ya que la naturaleza fónica de sus textos incorpora un valor añadido: el uso de figuras retóricas reconocibles gracias a una nomenclatura canónica. Dichas figuras formaban parte de una convención teatral generadora de expectativas receptoras en su contexto cultural, y su distinción, recogida en manuales que han pervivido hasta nuestros días, facilitan su 
traslación al público contemporáneo por parte de los distintos integrantes de la cadena de producción teatral, principalmente los actores y también el director como máximo responsable de la representación.

Dentro de esa cadena de producción ocupará, por razones obvias, un papel fundamental el traductor cuando se traslada el texto origen a un contexto cultural de distinto idioma. En el caso específico de una obra teatral, al proceso habitual de traducción general habrá que incorporar una atención especial a las pautas rítmicas subyacentes, cuya repercusión fónica se extiende por el original, para trasladarlas al texto resultante mediante un recurso equivalente si se pretende que resulte válida también para la representación. Noel Clark, traductor de la obra de Molière al inglés, reflexiona sobre el proceso aplicable a la especificidad teatral de una manera similar:

The translator's ear ought to be attuned to the speech rhythms of the foreign tongue. Failing that, as he sits in his study, reading the original text, how can he hope to hear the characters speak and see them move clearly enough for him to develop an empathy with the author, to catch his tone and understand his purpose? (Clark, 1996:24-5)

El propósito de este artículo es analizar las estrategias de traslación a un nuevo contexto cultural de dichas figuras, ritmos o pautas observables en el texto origen que denotan una hipotética intencionalidad autoral de producir un efecto fónico. La elección de la obra shakesperiana como corpus de análisis se debe principalmente a mi experiencia como traductor de seis obras del bardo universal que han sido puestas en escena en España utilizando mis textos meta. Incorporaré fragmentos originales de cuatro de estas obras (Hamlet, Ricardo III, Mucho ruido y pocas nueces y Noche de reyes) en las que se distinguen claramente figuras retóricas iterativas para contrastar distintas opciones traductoras tomadas diacrónicamente con un comentario al respecto.

\section{Aliteración vs. Cacofonía}


En toda mediación lingüística que es consecuencia de la traslación de un texto teatral origen a un código meta distinto, el traductor procura ser consciente de las maniobras creativas del autor para transmitir información y emoción a un receptor que realiza un esfuerzo interpretativo si percibe el beneficio comunicativo del mismo. La inmediatez de la descodificación auditiva puede requerir una manipulación traductora que vaya más allá del trasvase léxico-semántico a nivel de estructura superficial. Al quedar invalidada la glosa paratextual propia de la recepción lectora, el traductor tiende a incorporar su resolución intratextualmente, sin dejarla en manos de otros miembros de la cadena de producción teatral que pudieran desvirtuarla, aunque solo fuera por mero desconocimiento o descuido. La lógica asimetría interlingüística en las figuras de dicción que se basan en una coincidencia fonémica sin vinculación etimológica perceptible hace necesaria una modificación léxica, semántica e incluso sintáctica para recrear paronomasias, polisemias, homofonías u otros recursos fónicos basados en la iteración.

Si seguimos la «Teoría de la relevancia» propuesta por Sperber y Wilson, la intencionalidad emisora queda explícita mediante lo que denominan ostensive behaviour, un incentivo para la activación de la recepción según esta ampliamente referenciada cita: «An act of ostension carries a guarantee of relevance, and [that] this fact - which we will call the principle of relevance - makes manifest the intention behind the ostension» (Sperber y Wilson, 1986:50). Esta ostensión, en la temática que nos compete, se distinguirá por parte del receptor mediante la percepción de un efecto fónico, y por el traductor gracias a la identificación de la figura utilizada para producirlo. Con el reconocimiento de dicha voluntad comunicativa se iniciará el proceso de descodificación que permite deducir el pensamiento y la actitud del dramaturgo gracias a su incorporación de elementos identificables en el enunciado emitido. Y la complicidad receptora aumentará ante la vinculación fónica de dos o más lexías en situación de proximidad que compongan un efecto fónico recurrente pese a su difusa o inexistente relación etimológica.

Este planteamiento no implica que una misma figura de dicción disfrute de un reconocimiento similar en las distintas culturas. A este factor hay que añadir una evolución cronológica que trae consigo la modificación de convenciones de los códigos receptores. Por ejemplo, la figura retórica iterativa más básica, la aliteración, tenía un 
grado de aceptación mucho mayor en el contexto del teatro renacentista inglés que en el Siglo de Oro español. De hecho, el término «cacofonía» se suele vincular a la aliteración en sentido peyorativo, acepción inexistente para el término cacophony. La explicación a dicho contraste se puede encontrar en el hecho de que el teatro inglés no era rimado, por lo que la utilización de la aliteración era mucho mayor con el propósito de atraer una atención auditiva sobre lexías en situación de contigüidad.

En el teatro isabelino inglés, la utilización de esta figura era bastante habitual. En la obra histórica Ricardo III las alusiones al malvado protagonista que da título al texto, una vez se corona rey al final del tercer acto III, se circunscriben a una imaginería verbal que le vincula con un perro. En el acto siguiente se suceden voces de alarma en este sentido, y la recurrencia fónica se produce principalmente mediante el recurso de la aliteración. Margarita, la depuesta reina superviviente de la casa de Lancaster, le define así en el acto IV:

«A hellhound that doth hunt us all to death» (IV.iv.48)

La repetición del fonema alveolar $/ \mathrm{h} / \mathrm{al}$ inicio de tres palabras tan próximas concita una atención auditiva sobre la descripción metafórica del personaje en una elección léxica claramente deliberada. Estas son las soluciones traductoras encontradas en siete textos meta españoles de distintas épocas:

Hiráldez (1868) ese sabueso del infierno que á todos nos persigue de muerte;

Macpherson (1873) la fiera que tenaz nos corre;

Lafuente (1918) el infernal sabueso que nos ha perseguido de muerte á todos;

Astrana (1921) el infernal sabueso que nos ha perseguido de muerte a todos!

Valverde (1967) Un lebrel del infierno que nos persigue a todas hasta la muerte.

Cisternas (1974) el perro infernal que nos ha perseguido a todos a muerte.

Lázaro (1984) El can infernal que nos va cazando a muerte. 
Podemos comprobar cómo únicamente en las traducciones más recientes se encuentran dos términos coincidentes en su fonema inicial con una relativa proximidad (respectivamente el fonema oclusivo labial sordo /p/ en «perro» y «perseguido» en la propuesta de Cisternas, y el linguo-velar oclusivo sordo /k/ en «can» y «cazando» en la de Lázaro) aunque obstaculizados medialmente por el adjetivo «infernal» y un tiempo verbal compuesto. Por lo que respecta a mi traducción publicada (Sanderson, 1998), maticé la especie animal como «perro de presa» para potenciar el efecto aliterativo, antepuse el adjetivo al nombre para aumentar la proximidad y elegí un tiempo verbal simple para obtener como resultado: «un infernal perro de presa que nos persigue hasta la muerte». Una vez iniciados los ensayos propuse la omisión de la conjunción «que», siempre consciente de que podría haber otras opciones igualmente válidas.

Este primer análisis no pretende sugerir que haya que trasladar estructuralmente la misma figura retórica al texto meta; el objetivo sería únicamente el de reproducir un efecto ilocutivo equivalente, ya que, como afirma Aaltonen: «In the theatre, orality, immediacy and communality unavoidably introduce a new dimension to the translation of texts» (Aaltonen, 2000:41). Por ejemplo, en el mismo acto IV, Isabel, viuda del recién fallecido rey de Inglaterra Eduardo IV (y, por tanto, cuñada de Ricardo III), advierte a su hijo, el marqués de Dorset, de que su vida corre peligro por ser el legítimo sucesor de la corona, haciendo uso de una metáfora similar asociada al mismo campo léxico animal:

«Death and destruction dogs thee at thy heels» (IV.i.39)

La nueva aliteración del fonema oclusivo alveolar sonoro /d/ se logra mediante la situación de contigüidad de death, destruction y dogs, lexías todas ellas con una denotación semántica negativa en este contexto. Las propuestas traductoras en los siete textos meta citados anteriormente con respecto a este fragmento fueron las siguientes:

Hiráldez (1868) la muerte y la destrucción te persiguen y quieren cogerte; 
Macpherson (1873) La destrucción, la muerte te persiguen.

Lafuente (1918) ¡La muerte y la destrucción te persiguen!

Astrana (1921) ¡La muerte y la destrucción ladran en tus talones!

Valverde (1967) La muerte y la destrucción te muerden los talones;

Cisternas (1974) ¡La muerte y la destrucción son dos perros que ladran a tus talones!

Lázaro (1984) Muerte y destrucción te muerden los talones.

En este caso encontramos que son las traducciones de Valverde y, nuevamente, de Lázaro, las que denotan una mayor conciencia del efecto fónico; este último la hizo para una puesta en escena que él mismo dirigió y protagonizó en 1984. En ambos casos aproximan dos términos que no solamente comparten fonema inicial, sino que establecen una relación parónima entre «muerte» $\mathrm{y}$ «muerde», palabras con una connotación negativa diferenciadas por un solo fonema, y que no guardan ninguna relación etimológica entre sí, por lo que la impresión fónica producida es incluso mayor. Aquí se demostraría que no es necesario trasladar la misma figura retórica del texto original al texto meta para producir un efecto fónico equivalente. Resultaría incluso más efectivo invertir el orden de los sustantivos para incrementar la proximidad de las dos lexías que componen la figura retórica: «La destrucción y la muerte te muerden los talones.»

Pese a lo que acabamos de matizar, la repetición de la estrategia traductora sí parecería necesaria cuando se observe una regularidad isotópica en el texto origen vinculada a un campo semántico específico, para así mantenerla en el código meta aunque sea mediante un recurso distinto, pero recurrente. Esto sería aplicable en la obra citada, por ejemplo, cuando se observa la utilización de la aliteración del fonema linguo-alveolar sonoro /1/ en más de una ocasión para referirse peyorativamente a la hipotética vida sexual de Eduardo IV, monarca anterior a la proclamación de su hermano Ricardo III. En el siguiente fragmento, Buckingham, el lugarteniente del que será nuevo rey, compara las actividades cotidianas de los dos hermanos para ensalzar a este. 
«He is not lolling on a lewd love-bed,

But on his knees at meditation» (III.vii.71-2)

La aliteración se logra por la concentración en la misma línea de tres lexías que incorporan el fonema /1/ en posición inicial, lulling, lewd y love-bed. La regularidad de su utilización vinculada al campo semántico de la procacidad sexual [Ricardo aludía a su hermano Eduardo en el monólogo inicial de la obra quejándose de que «he capers nimbly in a lady's chamber to the lascivious pleasing of a lute.» (I.i.12-13)] podría deberse a que la propia articulación del fonema, que requiere que los labios permanezcan entreabiertos dejando ver la cara posterior de la lengua, sugiera incluso visualmente un gesto físico simbólicamente relacionado con el significado. Las propuestas de las traducciones anteriormente citadas son las siguientes:

Hiráldez (1868) no se mece en el voluptuoso lecho del reposo, sino que se postra de rodillas para servir a Dios y contemplarle.

Macpherson (1873) No en lecho impuro matinal descansa;

Orando está de hinojos.

Lafuente (1918) No se revuelca en el lecho del placer, medita de rodillas.

Astrana (1921) ¡No se revuelca en el blando sofá, sino que dobla sus rodillas a la meditación!

Valverde (1967) No está jugueteando en una lasciva cama en pleno día, sino arrodillado en meditación;

Cisternas (1974) ¡No se revuelca en muelles colchones, sino que dobla sus rodillas a la oración!

Lázaro (1984) No se inclina sobre el lascivo lecho de amor, sino sobre sus rodillas en meditación, 
Como podemos observar, es de nuevo Lázaro el único que traslada la figura iterativa al texto meta mediante la proximidad de las lexías «lascivo lecho», evidenciando una vez más su percepción de la representación como objetivo último del texto teatral original. El hecho de que repita la misma combinación fónica en otros apartados paralelamente a su aparición en el texto origen confirma su particular sensibilidad traductora orientada hacia la puesta en escena. Lo discutible, en todo caso, es si el resto de las propuestas hipotéticamente circunscritas a la publicación están haciendo una traducción adecuada, al no tener en cuenta estas deliberadas maniobras de composición creativa presentes en el texto origen.

\section{Iteración caracterizadora}

Si avanzamos un estadio más en el análisis de un texto origen hacia la iteración léxica, es decir, la consideración de la lexía como unidad mínima de análisis, la concentración de términos en búsqueda de un efecto fónico se produce no en función de que compartan el fonema inicial, sino en que las palabras en su totalidad coincidan en una reproducción fónica idéntica o similar. La descodificación referencial canónica aportada por una lexía cuando se enuncia por vez primera sufrirá, en consecuencia, una modificación por la ruptura de expectativas que produce una reaparición fónica inesperada con un término con el que no guarda un parentesco etimológico reconocible. Este fenómeno suele encontrarse comúnmente definido bajo el término general de paronimia, y cubre aspectos específicos vinculados a la homofonía, la homonimia, el retruécano o a lo tradicionalmente referido con el hiperónimo «juego de palabras».

La primera vez que aparece un recurso vinculado a la iteración léxica en la obra más popular de William Shakespeare, Hamlet, tiene lugar cuando el personaje que da título a la obra da una respuesta despectiva a las conciliadoras palabras de su tío Claudio:

«Claudius But now, my cousin Hamlet, and my son,--

Hamlet A little more than kin, and less than kind. » (I.ii. 66-7) 
El rechazo de Hamlet se debe a que el hermano de su padre se ha casado con su madre poco después de la muerte de este, por lo que alude a una relación familiar oficialmente más próxima, que viene determinada por la palabra kin, pero sentimentalmente más distante. Este último aspecto se aprecia mediante el consiguiente efecto ilocutivo que produce la aparición de una lexía de reproducción fónica similar, kind, que podría referirse tanto a la acepción de «amabilidad» como a la de «tipo, clase». En cinco traducciones encontramos las siguientes propuestas:

Astrana (1922)

Valverde (1967)

Molina Foix (1989)

Conejero y Talens (1992)

Pujante (1994)
Un poco menos que primado, y un poco más que primo.

Un poco más que pariente, y menos que padre.

Cuanto más parentesco, menos parecido.

Algo más que deudo y menos que hijo.

Más en familia, y menos familiar.

Podemos observar como en todas las traducciones, salvo en la de Conejero y Talens, la evidente similitud fónica del original incentiva a buscar un equivalente traductor en el texto meta para producir un efecto fónico similar que oscila entre la figura etimológica, el retruécano o la mera aliteración. Todas resultarían válidas en su intención de priorizar el efecto fónico sobre la precisión semántica (en este último extremo, las opciones de Molina Foix y Pujante serían las más cercanas), al ser percibida esa voluntad creativa en el texto origen.

Por otra parte, cuando la iteración léxica se produce a un nivel macrotextual en pasajes distantes en la obra (como observábamos en el caso de la última aliteración analizada vinculada al fonema /1/), la atención requerida es mayor, y más aún si tiene una repercusión en el argumento y/o en el perfil constitutivo de un personaje, como es el caso de la comedia que analizamos a continuación: Mucho ruido y pocas nueces. Aquí Shakespeare caracteriza a unos arquetipos cómicos mediante los repetidos lapsus léxicos en los que incurren: 
Dogberry y Vergés son, en principio, los personajes más difíciles de trasladar a un escenario español. Su repentina y tumultuosa entrada sin presentación alguna al principio del acto III sería acogida con una carcajada multitudinaria por el público isabelino, que reconocería al instante a los dos torpes alguaciles, tan habituales en el teatro de la época. (Sanderson, 1997:15)

Estas poco ejemplares figuras de la autoridad intentan reproducir palabras escuchadas previamente con tan mala fortuna que confunden los términos, fonética y/o semánticamente, produciendo un efecto humorístico que genera expectativas en el receptor cada vez que aparecen en una escena (solo cuatro de un total de las diecisiete escenas, pero que convierten a Dogberry en uno de los personajes más recordados). Este estereotipo popular en el contexto cultural origen no encuentra necesariamente un paralelismo en otros contextos, por lo que su caracterización verbal requiere un cuidado aún mayor para generar un cotexto específico en el texto meta, mediante la traslación de estas características verbales, que permita crear expectativas equiparables hacia el personaje. «All jokes depend on stereotypes, upon generalizations, and upon typicalities or representativeness which can easily -as we now easily know- constitute an abuse as well as be abusive» (Ricks, 1990:464). En el siguiente ejemplo nos encontramos con que uno de los asistentes de Dogberry alude a un sospechoso mediante la referencia a un rasgo físico. Cuando, dos actos después, cerca del desenlace de la obra, el alguacil reproduce la información que escuchó, entendemos, gracias a nuestro conocimiento contextual previo, que ha incurrido en un nuevo y característico error léxico:

«Second Watch «Dogberry
I know him, a wears a lock.» they say he wears a key in his ear, and a lock hanging by it,»

(III.iii.163-4)

(V.i.302-3)

Su asistente se había referido a un distintivo rizo del pelo del sospechoso, y Dogberry utiliza una lexía homónima, que identificamos, gracias a las lexías adyacentes, con una carga semántica atribuida a «candado». La interpretación errónea inicial por parte del alguacil de la acepción de lock le conduce a incorporar la lexía key (llave) por asociación semántica con la segunda acepción, lo cual facilita su descodificación en el texto origen. Encontramos en estas cinco traducciones las siguientes propuestas: 
Navarra (1868) Yo le conozco; va con unos rizos.

Dicen que lleva una llave en la oreja y un rizo colgado de ella,

Clark (1871) Le conozco: lleva un rizo.

Una llave en la oreja y colgado de ella un rizo.

Astrana (1929) Le conozco; lleva un rizo.

Dice que lleva una llave en la oreja y colgado de ella un rizo.

Valverde (1967) Le conozco, tiene pelo ensortijado.

Dicen que tiene el pelo con sortijas y anillos en las orejas,

Varela (1970) Yo le conozco; lleva un rizo en la cabellera.

Dicen que lleva una llave en la oreja, con un rizo colgando.

Como se puede observar, solo en la propuesta de Valverde se encuentra una solución traductora que transmita un lapsus léxico equivalente, en este caso mediante la utilización inicial de una metáfora fosilizada, «ensortijado», de la que extrae el lexema para utilizarlo con su valor semántico original en la segunda intervención. En el resto de los casos, se mantiene la carga semántica de la primera acepción, «rizo», en ambas intervenciones, perdiéndose el efecto ilocutivo original. Personalmente planteo sustituir la lexía «rizo» por «tirabuzón» para aprovechar que, mediante una falsa etimología, se pudiera interpretar como una palabra compuesta de «tira» $\mathrm{y}$ «buzón» (en realidad es un galicismo que procede de tire-bouchon) que justificara la confusión del alguacil y su referencia a una «llave» por su relación semántica con «buzón».

Las expectativas traductológicas con respecto a las dos obras mencionadas en este apartado habrían sido mayores hacia una comedia como Mucho ruido y pocas nueces que una tragedia como Hamlet, ya que la tipología creativa vinculada a la paronimia se asocia tradicionalmente con la producción de un efecto ilocutivo humorístico. La intervención isoléxica de Hamlet en el texto origen provoca un reconocimiento traductor fácilmente identificable del sarcasmo hacia su tío, pero la ausencia mayoritaria de una actuación traductora equivalente hacia la homonimia en la que incurre Dogberry 
plantea la duda de si se debe a un criterio de composición del texto meta o a una mera falta de percepción de dicha figura.

\section{In absentia muy presente}

Una casuística aún más compleja tiene lugar cuando la iteración léxica no se produce a nivel superficial por la presunción de que resulta innecesaria la presencia de ambos términos al deducirse implícitamente la referencia a una lexía no enunciada. Recurriendo a una locución latina, en este caso denominamos relación léxica in absentia a la formada entre un término enunciado y otro no enunciado pero evocado incluso con mayor peso semántico que el que está presente:

La relación in absentia crea siempre un enriquecimiento semántico, ya que al sentido denotativo de la unidad actualizada $x$ se sobreañade, en forma de connotación sugerida, el sentido de la unidad ausente en la que $x$ hace pensar. La relación in praesentia se conforma con reforzar el vínculo existente entre las dos unidades. Así, por ejemplo, la paronomasia agrega a la relación semántica denotativa una conexión connotada por el parecido fonético, instaurando además una connotación estilística, ya que la explotación sintagmática de una relación paradigmática particular produce en general el efecto retórico de una figura. (Penas Ibáñez, 2009: 94)

Esta connotación estilística se vincularía, en el caso anteriormente extraído de Mucho ruido y pocas nueces, a las características inherentes a la torpeza del alguacil reveladas mediante la utilización de un término homónimo erróneo que contribuía a perfilar al personaje. Pero en una relación in absentia el reto traductor es mayor, ya que consistiría en aportar una lexía en el texto meta que materialice la incompetencia formal del arquetipo y así mismo evoque otro término ausente, proceso dificultado en mayor medida por la habitual asimetría interlingüística.

En el siguiente fragmento, Dogberry recrimina a los sospechosos detenidos el hecho de que no guarden las formas ante él (actitud generada en ellos por las repetidas equivocaciones del alguacil), y para hacerlo incurre en otro error léxico: 
«Dost thou not suspect my place? Dost thou not suspect my years?»

Las lexías adyacentes al término erróneo, suspect, permite al receptor del texto origen descodificar que el enunciado pretendido y no realizado es respect por los términos a los que va referido, y gracias también a la esencial coincidencia paronímica en la secuencia fonémica final de ambos términos. La identificación del error viene apoyada, además, por las expectativas creadas anteriormente con respecto al personaje, y el hecho de que suspect tenga una carga semántica antonímica de respect contribuye así mismo a potenciar el efecto humorístico.

La asimetría fónica producida en el contexto meta, ante las obvias diferencias fonéticas entre «sospechar» $\mathrm{y}$ «respetar», hipotéticamente obligaría al traductor a manipular la lexía presencial para evocar fónicamente una lexía ausente vinculada antónimamente a la misma. En las traducciones anteriormente citadas encontramos las siguientes propuestas:

Navarra (1868) ¿Qué? ¿No te impone respeto mi cargo? ¿Tampoco respetas mi edad?

Clark (1871) ¿No te difunde respeto mi cargo? ¿No te difunden respeto mis canas?

Astrana (1929) ¿No te infunde sospecha mi cargo? ¿No te infunde sospecha mi edad?

Valverde (1967) ¿Sin respecto para mi cargo, sin respecto para mis canas?

Varela (1970) ¿Es que no sospechas mi cargo? ¿No sospechas mi edad?

Podemos observar como en dos de las traducciones aparece la lexía in praesentia del original, en otras dos la lexía in absentia, y solo en la propuesta de Valverde encontramos un término parónimo vinculado fónicamente a ambas, con la única diferencia de la presencia medial del fonema $/ \mathrm{k} /$, pero cuya carga semántica difumina toda posibilidad de relación antónima. Puede ser ilustrativa en su utilidad, sin embargo, 
la estrategia compartida por Clark y Astrana de modificar en el enunciado un término de una unidad fraseológica, «infundir respeto», para orientar al receptor hacia el hecho de que es dicha colocación la que el alguacil pretende decir sin éxito. En este sentido, recomendaría persistir en la propuesta de Clark sustituyendo el primer término por otro igualmente parónimo, pero con una carga semántica negativa para contribuir al efecto humorístico: « ¿No te confunde respeto mi cargo? ¿No te confunden respeto mis canas?» El contenido explícito expuesto en la estructura superficial conduciría, por tanto, a un proceso de inferencia por parte del receptor que agilizaría el proceso descodificador. Pero todo empezará por el estado de alerta permanente de quien lo ha de trasladar al texto meta, en este caso para perfilar la identidad del personaje: «La detección de un recurso estilístico iterativo por parte de un traductor contribuye a aportar una mayor coherencia macrotextual» (Sanderson, 2009:81).

La tradicional dicotomía vinculada a la traducción teatral que Zuber (1984) incluso utilizó para titular un volumen editado por él, Page to Stage (que, interesantemente, hace uso de una paronimia), parece que requiera una adscripción inquebrantable en una u otra dirección sin que necesariamente tenga que ser así. En este sentido, utilizaremos un último fragmento de otra comedia shakesperiana aún no mencionada en este artículo, Noche de reyes, donde ambas posiciones hipotéticamente enfrentadas podrían encontrar una justificación.

En el primer diálogo que se produce en esta comedia, el duque Orsino languidece por su amor no correspondido hacia la noble Olivia, y desarrolla una metáfora sobre su situación sentimental en la que se entrecruzan vínculos isoléxicos e intertextuales:

«Curio

Will you go hunt, my lord?

Duke Orsino

What, Curio?

Curio

The hart.

Duke Orsino

Why, so I do, the noblest that I have:

O, when mine eyes did see Olivia first,

Methought she purged the air of pestilence!

That instant was I turn'd into a hart; 
And my desires, like fell and cruel hounds,

E'er since pursue me.» (I.i.16-24)

La enunciación de la lexía presencial, hart, es idéntica a la ausente, heart, con la que se genera una homofonía in absentia vinculada semánticamente a la encrucijada romántica en la que se encuentra el personaje. Simultáneamente, Shakespeare hace una alusión a la mitología griega, recogida en la Metamorfosis de Ovidio, estableciendo un paralelismo entre Orsino y Actaeon, un joven cazador que involuntariamente presenció como la casta Diana, diosa de la caza, se bañaba desnuda, y esta, en represalia, le convirtió en un ciervo que acabó devorado por sus propios perros.

Encontramos las siguientes traducciones de este fragmento:

Clark (1873) ¿Quereis cazar, señor?

¿Qué, Curio?

El ciervo.

Tal hago, y al más noble de los mios.

¡Ay! cuando á Olivia ví por vez primera,

El aire con su aliento embalsamaba.

En el instante aquel troquéme en ciervo;

Y desde entónces como alanos crudos

Me acosan mis deseos.

Astrana (1924) ¿Os agradaría cazar, señor?

¿Qué, Curio?

Corzas.

Pues eso hago, y con la más noble que he visto. ¡Oh! Cuando mis ojos contemplaron por primera vez a Olivia, me pareció que purificaba el aire de toda pestilencia. En aquel instante quedé 
transformadoen ciervo, y mis deseos, como sabuesos despiadados y crueles, no cesan de acosarme desde entonces.

Pujante (1996) ¿Vais a cazar, señor?

¿Qué, Curio?

La corza.

Ya lo hago; la más noble que hay. Cuando la vi por vez primera, Olivia purificaba el aire pestilente. Me convertí al instante en una corza y, desde entonces, mis deseos me persiguen como perros crueles y feroces.

Como se puede observar, en ninguna de estas propuestas tan cronológicamente distantes se ha tenido en cuenta la homofonía planteada in absentia en el original, priorizando la narración intertextualmente vinculada al relato mitológico frente a la interpretación académica mayoritaria de que the noblest that I have es una alusión a su corazón mediante la figura retórica utilizada: «The pun on hart (stag) and 'heart' is an Elizabethan commonplace. Orsino hunts his own heart, a suggestion of narcisism» (Elam, 2008:163). Podría deducirse, por tanto, que los autores isabelinos, Shakespeare incluido, optan por la utilización de dicho término en función de su homofonía con heart, y que si no hubiera existido ese paralelismo fónico, quizás el relato mitológico ni siquiera habría sido utilizado en este texto.

Ante la disparidad fónica entre «corazón» y «ciervo», «corza» u otros términos sinónimos, la debatible cuestión subsiguiente, extensible a todo este artículo, es hasta dónde se puede apartar el traductor semánticamente del término original para lograr una relación paronímica que produzca un efecto fónico equivalente. En mi caso, para la puesta en escena de esta obra, estrenada el 18 de mayo de 2011, opté por otro animal, «oso», para desarrollar una homofonía con el presente de indicativo del verbo «osar» («El oso. - Oso yo ser el cazado. Cuando la vi por vez primera...»), después de haber barajado paronimias que no me satisfacían tanto (por ejemplo: «- La liebre. - Libre era yo, hasta que la vi por vez primera...»), pero que también podrían haber sido válidas siempre que se aceptara mantener el vínculo con la cacería pese a que se diluya la 
referencia mitológica. Como afirma Aaltonen: «A translation always rewrites the source text, and it can never be an exact replica of it. In theatre translation this is an important consideration» (Aaltonen, 2000:72). El saludable debate seguirá abierto.

\section{Conclusiones}

La cuestión planteada en este artículo es la priorización de la naturaleza fónica del texto teatral en su traducción ante la percepción de una deliberada maniobra retórica realizada durante el proceso creativo del texto origen. En los siete fragmentos extraídos de cuatro obras de William Shakespeare como corpus de análisis hemos podido comprobar cómo el bardo universal hace un uso reconocible de figuras retóricas procedentes de la nomenclatura clásica establecida para vincular conceptos por medio de recursos iterativos que tendrían una repercusión fónica inmediata en un periodo donde se escribía exclusivamente para la puesta en escena. Esto no quiere decir que dramaturgos de épocas posteriores escriban pensando prioritariamente en la publicación, pero en el caso del teatro isabelino sí constituye un hecho objetivo.

Ante la disyuntiva entre la traducción individual de los términos semántica y fónicamente aislados o abordar la manipulación traductora de la figura retórica iterativa en su conjunto, aquí hemos optado por defender la segunda posibilidad al considerar que es la más adecuada al fin al que se destinaba. Incluso si actualmente se redujera su utilización a la lectura, aun así se recomendaría una manipulación que fuera más allá de la suma individual de cargas semánticas de las lexías presentes en la estructura superficial del texto origen, ya que también se podría hacer uso del paratexto explicativo en uno $\mathrm{u}$ otro sentido, un recurso, por cierto, infrautilizado en las traducciones publicadas consultadas. En este sentido, estamos de acuerdo con Gostand en su artículo sobre traducción teatral: «Irony, double entendre, wordplay and puns must be communicated if the spirit of the original is not to be lost» (Gostand, 1980:2).

En la traslación a un código meta de estas figuras es difícil que coincidan las formas fónicas de dos o más palabras del texto origen que no mantienen una relación etimológica entre sí. La desverbalización superficial de los enunciados se haría, por tanto, necesaria para que, una vez interpretadas las proposiciones de base, se trasladen 
las figuras al texto meta mediante un efecto fónico equivalente, aunque requiera un ajuste léxico que se distancie denotativamente de los términos originales. La manipulación y la atención traductora requeridas serán aún mayores cuando se trate de una iteración léxica in absentia para evidenciar, precisamente, el término que no aparece en el texto. Aunque desde una perspectiva más genérica, lo que afirma John Clifford sobre su experiencia como traductor de Calderón de la Barca, Tirso de Molina y Cervantes al inglés también es aplicable aquí: «What is left unsaid matters as much as what is said, and as translators we have to be sensitive to both. And if we do our job properly, we can open out such amazing new perspectives to our audience» (Clifford, 1996:264).

Por tanto, de igual forma que comprobábamos cómo una recurrencia isoléxica caracterizaba a un determinado personaje, Dogberry, y como se podía manipular el texto origen para que dicho rasgo distintivo de su perfil perviviera en el nuevo contexto, la recurrente estrategia traductora de un profesional también parece seguirle caracterizando como orientado hacia page o stage, cuando idealmente sería hacia ambos, ya que dichos términos no son necesariamente excluyentes.

\section{Referencias bibliográficas}

Aaltonen, S. (2000). Time Sharing on Stage: Drama Translation in Theatre and Society. Clevedon: Multilingual Matters.

Clark, N. (1996). Translating for the love of it. En Johnston, D. (ed.) Stages of Translation. Bath: Absolute Classics, pp. 23-34.

Clifford, J. (1996). Translating the spirit of the play. En Johnston, D. (ed.) Stages of Translation (pp. 263-70). Bath: Absolute Classics.

Gostand, R. (1980). Verbal and Non-Verbal Communication: Drama as Translation.-En Zuber O. (ed.) The Languages of Theatre: Problems in the Translation and Transposition of Drama (pp. 1-9). Oxford: Pergamon Press.

Johnston, D. (2000). Valle-Inclán: The Meaning of Form.-En Upton, C.A. (ed.) Moving Target: Theatre Translation and Cultural Relocation (pp. 85-100). Manchester: Saint Jerome. 
Penas Ibáñez, A. (2009). Cambio semántico y competencia gramatical. Madrid: Iberoamericana Vervuert (Lingüística Iberoamericana).

Ricks, C. (1990). Word Making and Mistaking.-En Ricks C. y Michaels L. (eds.) The State of the Language (pp. 460-6). Londres: Faber \& Faber.

Sanderson, J.D. (2009). Hacia una tipología del malapropismo shakespeareano y sus estrategias de traducción.-TRANS Revista de traductología (nº9) 71-82. Málaga: UMA.

Sperber, D. y Wilson D. (1986). Relevance: Communication and Cognition. Oxford: Blackwell.

Zuber, O. (ed.) (1984). Page to Stage: Theatre as Translation. Amsterdam: Rodopi.

\section{Fuentes bibliográficas utilizadas para el análisis del corpus}

Shakespeare, W. (1591). King Richard III. Anthony Hammond (ed). 1981. The Arden Shakespeare. Londres: Methuen. 1987.

Hiráldez de Acosta, M. (1868). Ricardo III. Madrid: Nacente. 1872.

MacPherson, G. (1873). Ricardo III. Madrid: Edaf. 1997.

Martínez Lafuente, R. (1915). Obras completas de Shakespeare: Vol. 10. La tragedia de Ricardo III. Valencia: Prometeo.

Astrana Marín, L. (1921). Obras completas de William Shakespeare: Vol. 1. La tragedia de Ricardo III. Madrid: Aguilar. 1932.

Valverde. J.M. (1967). Obras Completas. Ricardo III. Barcelona: Planeta.

Cisternas L. (1974). Hamlet - Ricardo III - Enrique V. Barcelona: Bruguera.

Lázaro, E. (1984). Ricardo III. Madrid: Valdemar. 1997.

Sanderson, J.D. (1998). La tragedia del rey Ricardo III. Alicante: Aguaclara.

Shakespeare, W. (1598). Much Ado About Nothing. Humphreys, A. R. (ed.) (1981).

Londres y Nueva York: Arden.1994.

Navarra Farré, J. (1868). Mucho ruido y pocas nueces. Barcelona: Ediciones B. 1997. 
Clark, J. (1871). Mucho ruido para nada. Madrid: Medina y Navarro.

Astrana Marín, L. (1929). Mucho ruido y pocas nueces. Madrid: Aguilar. 1981.

Varela, R. (1946). Mucho ruido y pocas nueces. Barcelona: Iberia. 1970.

Valverde, J. M. (1967). Obras completas. Mucho ruido y pocas nueces. Barcelona:

Planeta

Sanderson, J.D. (1997). Mucho ruido y pocas nueces. Alicante: Universidad de

Alicante.

Shakespeare, W. (1600-2). Hamlet. Thompson, A. y Taylor, N. (ed.) 2010. The Arden Shakespeare. Londres: Methuen.

Astrana Marín, L. (1922). Hamlet. Madrid: Espasa-Calpe. 1978

Valverde, J. M. (1967). Obras Completas. Hamlet. Barcelona: Planeta

Molina Foix, V. (1989). Hamlet. Madrid: Centro Dramático Nacional.

Conejero, M.A. y Talens, J. (1992). Hamlet. Madrid: Cátedra.

Pujante, A.L. (1994). Hamlet. Madrid: Espasa-Calpe. 2010.

Shakespeare, W. (1601). Twelfth Night or What you will. Elam, K. (ed.) 2008. The Arden Shakespeare. Londres: Methuen.

Clark, J. (1873). Obras de Shakespeare: La tempestad; La noche de Reyes. Madrid: Medina $\quad \mathrm{y}$ Navarro. [Recuperado online] http://emothe.uv.es/biblioteca/textosEMOTHE/EMOTHE0188 LaNocheDeReyesOLo QueQuerais.php (Consultado el 10 de marzo de 2017)

Astrana Marín, L. (1924). Noche de Epifanía. Colección Universal n n 905 y 906. Madrid: Calpe.

Pujante, A.L. (1996). El sueño de una noche de verano. Noche de reyes. Madrid: Espasa-Calpe. 